\title{
Compassion Saves Lives
}

\section{Steven L. Proctor ${ }^{1}$}

Received: 9 December 2019 / Accepted: 21 January 2020 / Published online: 23 January 2020

(C) Academic Psychiatry 2020

Emergency department;

overdosed again.

Contaminated supply.

Cold, sterile hospital bed.

Treated with warmth, compassion.

Leave with hope, medication.

Early recovery,

taking it day by day

until the next relapse.

Alone; I'll do just one.

A comforting warmth, for now.

Tears. What have I done?

Sixty days sober,

followed by another slip.

Please don't give up on me.

In remission now.

Married, expectant father.

New lease on life.

Warm, welcoming bed.

My son storms in, excited;

"Happy birthday, dad!"

Poet's Statement In light of the ongoing opioid overdose epidemic and call to action for evidence-based, harm reduction strategies and increasing access to medications for opioid use disorder, I believe it is important to humanize this crisis and bring attention to the role of compassion in medicine. This poem draws from the lived experiences of people with opioid use disorder I have treated as well as national trends. In particular, there is one individual who shared with me that even momentary, seemingly insignificant acts of kindness by hospital staff in the context of his treatment had a lasting impact on his life. I also learned that life events and milestones such as marriage, kids, and birthdays begin to take on new meaning in recovery. In my work, I have come to appreciate that despite current conceptualizations of addiction as a chronic, relapsing condition, it is treatable-effective treatments exist and recovery is possible. Out of respect for people with substance use disorder and people who use drugs, I would never claim to be their voice, but I do see it as my responsibility to speak out on their behalf and share my experiences in working with them, and hopefully reduce stigma along the way. This poem is an open invitation to all health care professionals - from first-year trainees to seasoned physicians - to be an advocate. It requires no formal training and education to be kind.

\section{Compliance with Ethical Standards NA}

Ethical Considerations NA

Disclosure The author states that there is no conflict of interest.

Publisher's Note Springer Nature remains neutral with regard to jurisdictional claims in published maps and institutional affiliations.

Steven L. Proctor

sproctor@thrivingmind.org

1 Thriving Mind South Florida, Miami, FL, USA 